\title{
SCIENCE.-Supplement.
}

FRIDAY, OCTOBER 29, 1886.

\section{PRELIMINARY NOTE OF AN ANALYSIS OF THE MEXICAN CODICES AND GRAVEN INSCRIPTIONS. ${ }^{1}$}

I wISH to make a statement of a few of the results I have recently obtained by a translation into the Nahuatl language of the phonetic symbols contained in the Vienna codex and the Bodleian and Selden manuscripts. I find that these entire codices are composed of signs representing parts of speech, forming, in combination, words and sentences. Moreover, I have discovered certain determinative signs that render a misinterpretation of these picture-writings impossible.

The Vienna codex, the Bodleian and Selden manuscripts, are records of lands, tributes, tithes, and taxes. A partial decipherment of portions of the Borgian, Vatican, and Fejérvary codices convinces me that these do not relate, as has been supposed and is maintained, to astrological and exclusively religious matters, but deal with the details of a communal form of government, the existence of which has been suggested by some recent writers, but not sufficiently proved to be generally accepted.

The as yet imperfect insight I have obtained through these native works confirms and completes much of the testimony of the early Spanish writers, but also renders evident the false and distorted impressions they received and handed down.

Familiarity with certain phonetic symbols of frequent recurrence in the picture-writings caused me to perceive, somewhat to my astonishment, that identical symbols are reproduced on the so-called 'calendar stone,' the 'sacrificial stone,' and other equally well known monoliths. Through the decipherment of these and an application of the same method to other symbols engraved thereon, I unhesitatingly affirm, even at this early stage of investigation, that these graven monoliths are not what they have hitherto been considered. On them are Nahuatl words that are found in the codices in Sahagun's invaluable 'Historia,' and in other early chronicles where imperfect explanations of them are given ; and these words reveal, beyond doubt, the true uses and purposes of the stones.

1 Read before the American association for the advancement of science at Buffalo, August, 1886.
Let us cursorily examine the testimony of the best authorities on a certain point. Duran tells us distinctly that there was in each market-place of ancient Mexico a circular, elaborately carved tablet, held in great veneration. It was frequently consulted, and by it the market-days were regulated. All writers concur in stating that the market was held on each fifth day. According to them, a period of five days answered to our week, and four such divisions formed the period of twenty days termed the Mexican month. They tell us that all adults were obliged by law to resort to the appointed market-place on each fifth day, and that all produce and manufactures had to be brought there, even from great distances, severe penalties being incurred by those who bartered the produce of land or labor on the highway or elsewhere. On the broad, straight, cemented roads leading to the locality of each market, ' resting-places' for the wayfarers and carriers were provided at regular intervals ; and, by the number of such stopping-places between one point and another, distances were estimated.

The enormous concourse of people, the variety of produce exhibited, and the order that prevailed in the markets of Mexico and Tlatelolco, filled the conqueror with wonder and admiration. From Cortes, Bernal Diaz, Sahagun, and others, we learn that the market was a special charge of the supreme chief of Mexico ; that appointed officers presided in state over it, while others moved among the throng superintending the traffic. Standard measures were kept, and rigorous punishment awaited those who sold by false measure or bartered stolen goods.

It is my opinion, and one that I can support by a mass of further corroborative evidence, that the periodical market-day was the most important regulator of the Mexican social organization, and that the monolith generally known as the calendarstone was the market-stone of the City of Mexico. It bears the record of fixed market-days ; and I venture to suggest that from these the formation of the Mexican calendar system originated. The stone shows the existence of communal property and of an equal division of general contributions into certain portions. I find, moreover, that the face enclosed in the inner circle of the tablet is a rebus. When its several parts are interpreted by the phonetic elements they represent, a sentence is obtained which clearly shows the use of the tablet. Of this sentence I shall submit but two 
words, deeming these sufficient, for the present, to prove my method and its results.

Thus from the phonetic elements tetl ('stone'), ixtli (' face or surface'), pan (' upon'), is obtained, by combination, according to rules of the Nahuatl grammar, the word teixpan, meaning ' publicly.'
Now, turning to the monolith generally known as the sacrificial stone, $I$ find it to be a law-stone of similar nature, recording the periodical collection of certain tributes paid by subjugated tribes and others whose obligation it was to contribute to the common wealth of Mexico. A symbolic

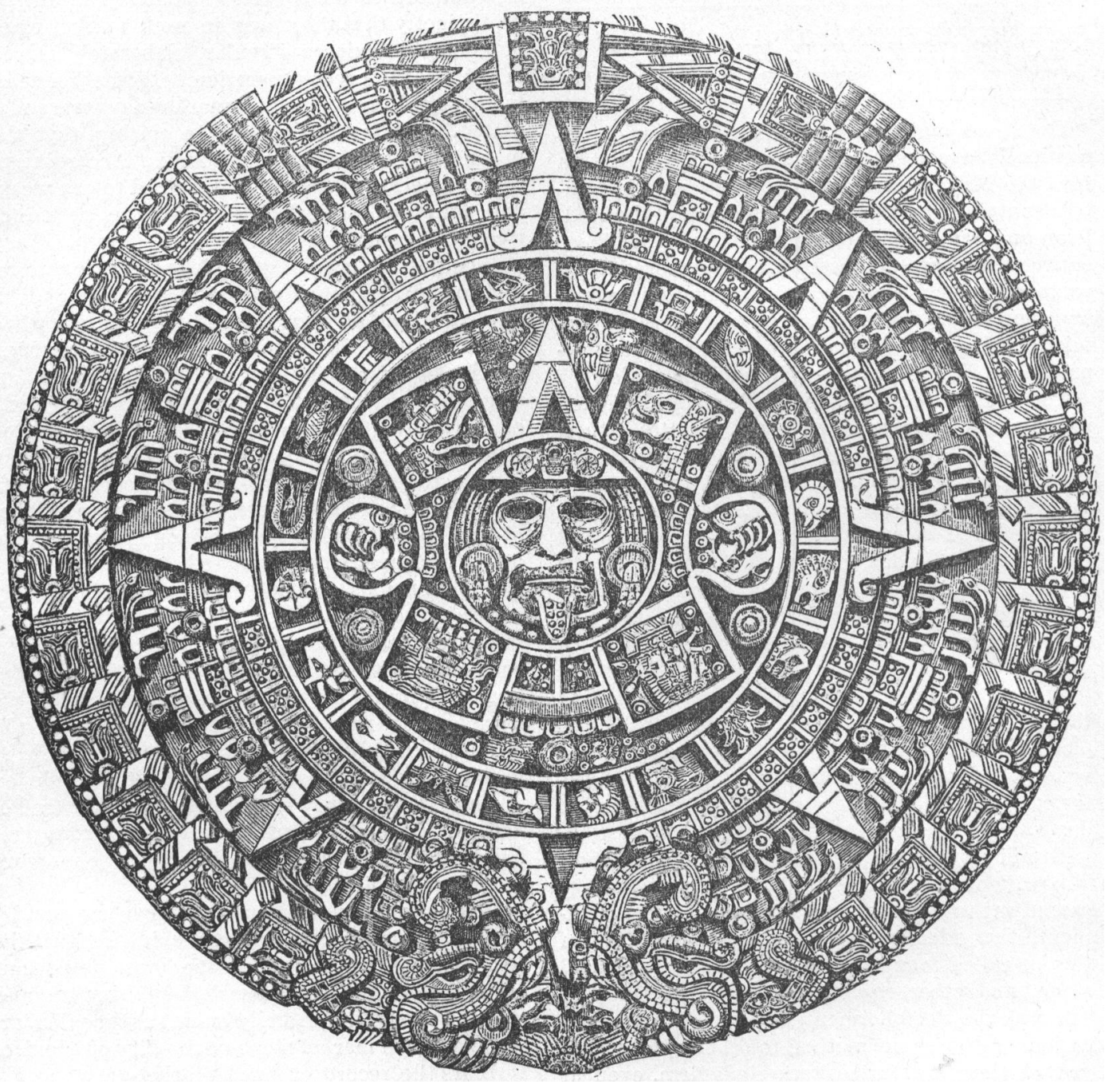

THE MEXICAN CALENDAR-BTONE.

In Molina's dictionary the noun teixpanca is translated as 'something evident and manifest to all.' The protruding tongue yields the two elements of the word nenepilquica (' to mark, note, keep account of '), formed by nenepilli ('tongue') and quica (' to go out'). These statements are, of course, almost meaningless to any but Nahuatl students acquainted with the pictographie system. frieze around the stone consists of groups, placed at intervals, of flints (tecpatl), with conventionally carved teeth (tlantli), giving, in combination, the word tecpatlantli. This word occurs in Sahagun's 'Historia' as the name given to the ' lands of the palace,' and in one of the native works I find designated the four channels into which the produce of these lands was diverted. 
The periods indicated on it differ from those on the great market-stone, and seem to furnish a solution to the perplexing complementary calendar system mentioned by Spanish writers as 'the lords of the night accompanying the days.'

In conclusion, I would state, that, in my opinion, many of the large stone receptacles that are generally called 'vessels for containing the hearts and blood of human victims' are no other than the standard measures, preserved for reference in the market-place.

Before publishing my final results, I shall submit them to a searching and prolonged in restigation. An examination of the originals of many of the codices reproduced in Lord Kingsborough's 'Mexican antiquities' will be necessary to determine important points, and during the forthcoming year my line of researches will be in this direction.

Zelia NutTall.

\section{HOW TO MAKE THE MOST OF A SMALL LIBRARY. ${ }^{1}$}

THE question is not what to do with a library of five hundred thousand, or a hundred thousand, or fifty thousand volumes. It has nothing to do with libraries which can afford to buy manuscripts or incunabula, black-letter tracts, or early American sermons. It is not for libraries whose collections of original authorities took away, many years ago, the cause of John Adams's reproach that in his time the books from which Gibbon's statements might be proved true or false could not be found in the United States. A student may go to the libraries in the great cities and read at his will, order from abroad books relating to his specialty, or, if he can show just cause for his request, may even have books sent to his distant home. The libraries which concern us are those of thirty, or ten, or five, or even of one thousand volumes, in towns and villages, open, perhaps, all day six days in the week, or two or three hours on one day. I mean this for you, whose library spends a thousand dollars a year; and you, who have but five hundred for books, periodicals, and binding; and you, who struggle along with fifty dollars' worth of new books twice a year. It is for you, too, whose library has existed in a half-alive state with poor American reprints of English books, novels in wretched condition, antiquated volumes of science, biographies of the dreariest, incomplete volumes of magazines. How can such libraries be made centres of sweetness and light in country towns?

' Your house is not large enough to swing a cat in,' said a man to his friend. ' But I don't wish

1 Read before the Milwaukee meeting of the Library association by Miss C. M. Hewins, July 7, 1886. to swing a cat,' answered the friend. This bit of homely wisdom, and another, ' When you can't have what you like, you must like what you have,' are as useful in libraries as anywhere else.

But they do not mean that you are to be satisfied with the present use of many of the books which are now gathering dust upon your shelves. Some of them may easily be made to answer the questions of your readers. Spend the next money that you have in a few books of reference, a new edition of an encyclopaedia, a good atlas, 'Lippincott's biographical dictionary,' ' Poole's index,' and its co-operative supplement the Brooklyn catalogue, and the Providence reference-lists. If you can get also, or if you have already, all the volumes of Harper's magazine, Scribner's monthly, and the Century, the Popular science monthly, and Littell's living age, with the separate indexes, including articles and poems too short to be indexed in Poole, you are ready to meet the wants of most of your readers. If you have time, index st. Nicholas, Wide awake, and Harper's young people. A librarian of a small library can often satisfy a reader by showing him an article written ostensibly for children, but told in the clear, simple style which appeals to many older persons. The thinking powers of many boys and girls never develop after they leave school at fifteen; and knowledge, in order to be attractive to them in their later years, must be set forth as attractively as in their school-days. If you can overcome the repugnance of many persons to books which they think childish and beneath them, you can often give them just what they are able to enjoy. I sometimes say, "The best article that $I$ know is in the Wide awake [or St. Nicholas, or Harper's young people], and, if you have no objection to reading a boys' and girls' magazine, I think that you will find in it just what you need."

A magazine which has a department of 'Answers to correspondents' asked, in a late number, for no questions which might be answered by referring to an encyclopaedia or biographical dictionary. In the next number a correspondent begged the editor to remember that many persons had no access to such books, and their only way of learning what they wished to know was through the magazine. The library in every town or village should supply this want, and should also contain Brewer's 'Reader's hand-book' and 'Dictionary of phrase and fable' (which, though often inaccurate, are much better than nothing), and Wheeler's 'Dictionary of noted names of fiction,' and 'Familiar allusions.' As soon as you can afford it, buy all the volumes of 'Notes and queries;' but until then you can answer many questions from the books of reference already named. 